\title{
El desarrollo jurisprudencial de la suspensión del derecho al sufragio en México
}

\section{María del Carmen Alanís Figueroa*}

\section{Sumario:}

I. Introducción

II. La Sala Superior del TEPJF y el artículo 38, fracción II, constitucional (SUP-JDC-85/2007)

III. La Primera Sala de la SCJN y el artículo 38, fracción II, constitucional (contradicción de tesis 29/2007)

IV. La sentencia del pleno de la SCJN recaída a la contradicción de tesis 6/2008-PL

V. Reflexiones

VI. Bibliografía y otras fuentes

* Magistrada de la Sala Superior del Tribunal Electoral del Poder Judicial de la Federación

D. R. @ 2012. Universidad Nacional Autónoma de México-Instituto de Investigaciones Jurídicas. 


\section{Introducción}

Desde su redacción original por el Constituyente de 1917, el artículo 38, fracción II, de la Constitución Política de los Estados Unidos Mexicanos (CPEUM) ha previsto como una de las causas que suspende los derechos o prerrogativas de los ciudadanos, estar sujeto a un proceso criminal por delito que merezca pena corporal, a contar desde la fecha del auto de formal prisión.

La literalidad de ese dispositivo pareciera no generar duda alguna sobre su aplicabilidad y consecuencias, en lo que respecta a las restricciones que impone a las y los ciudadanos en el ejercicio de sus prerrogativas previstas en el artículo 35 de la propia ley fundamental, principalmente, sobre las de votar y ser votados en las elecciones populares, a que se refieren las fracciones I y II de ese dispositivo constitucional.

Sin embargo, la inmutabilidad de ese precepto no fue obstáculo para que en 2007, la Sala Superior del Tribunal Electoral del Poder Judicial de la Federación (TEPJF) conociera sobre un caso contencioso $^{1}$ que enfrentó a un ciudadano con el Instituto Federal Electoral (IFE). Dicha autoridad le negó al primero la expedición de su credencial para votar con fotografía, a partir de la existencia en sus registros de un auto de formal prisión por el que había sido suspendido en sus derechos conforme a lo previsto en el precepto constitucional que será motivo de este análisis.

Su estudio y resolución obligó a ese órgano judicial especializado en la materia electoral, a realizar un examen vanguardista de esa causa de suspensión de los derechos ciudadanos, a partir de que el actor realizó los trámites de su alta en el padrón electoral y de su credencial para votar, gozando de libertad bajo caución.

El resultado de dicho examen fue dotar desde la óptica del derecho electoral, de un nuevo significado a esa norma constitucional de tipo restrictivo, para el efecto de que su aplicación quedara restringida sólo a aquellos casos en que la o el ciudadano se encontrara privado de su libertad. Esta lectura obedeció a una realidad que se impone a todas las autoridades del país, el deber de proteger y priorizar al máximo posible el ejercicio de los derechos humanos, entre los cuales se ubican los arriba enunciados.

1 Sentencia dictada el 20 de junio de 2007 en el expediente SUP-JDC-85/2007. 
Menos de un año después que la Sala Superior del TEPJF elevara ese precedente a la tesis XV/2007 de rubro: SUSPENSIÓn DE LOS DERECHOS POLÍTICO-ELECTORALES DEL CIUDADANO PREVISTA EN LA FRACCIÓN II DEL ARTÍCULO 38 CONSTITUCIONAL, SÓLO PROCEDE CUANDO SE PRIVE DE LA LIBERTAD, ${ }^{2}$ concretamente el 25 de febrero de 2008, se denunció ${ }^{3}$ ante el pleno de la Suprema Corte de Justicia de la Nación (SCJN), la posible contradicción de tesis entre dicho criterio de la Sala Superior del TEPJF y el emitido por la Primera Sala de la SCJN al resolver la contradicción de tesis 29/2007 de la que se integró la jurisprudencia número 1a./J.171/2007 de rubro: DeReChos políticos. DEBEN DECLARARSE SUSPENDIDOS DESDE EL DICTADO DEL AUTO DE FORMAL PRISIÓN, EN LOS TÉRMINOS DEL ARTÍCULO 38, FRACCIÓN II, de la Constitución Política de los Estados Unidos MexicaNos. ${ }^{4}$

La denuncia fue registrada en el pleno de la SCJN, bajo la contradicción de tesis 6/2008-PL y su análisis y resolución, ${ }^{5}$ por demás reciente, dio lugar a una importante serie de criterios, entre los cuales sobresale por su relación con este artículo, el que se recogió en la tesis de jurisprudencia del pleno 33/2011 de rubro Derecho al voto. SE SUSPENDE POR EL DICTADO DEL AUTO DE FORMAL PRISIÓN O DE VINCULACIÓN A PROCESO, SÓLO CUANDO EL PROCESADO ESTÉ EFECTIVAMENTE PRIVADO DE SU LIBERTAD.

Por su relevancia para la justicia constitucional electoral y para promover la difusión de aquellos criterios jurisdiccionales que se consideran sobresalientes para el ejercicio de los derechos político-electorales de los ciudadanos, este artículo se dedica a diseccionar, en orden cronológico, los componentes de la contradicción de criterios aludida $\mathrm{y}$ a formular, por último, algunas breves reflexiones con la finalidad de seguir aportando elementos que se desprenden del caso particular, así como contribuir a la todavía inacabada interpretación pro homine del artículo 38, fracción II, de la ley fundamental.

2 La tesis en comento fue aprobada en la sesión pública del 21 de septiembre de 2007.

3 Denunció la posible contradicción de tesis el ministro José Ramón Cossío Díaz.

4 El 31 de octubre de 2007, la Primera Sala de la SCJN resolvió la contradicción de tesis 29/2007 e integró la jurisprudencia número 1a./J.171/2007.

5 Sesiones públicas del 7 de enero de 2010 y del 26 de mayo de 2011. 


\section{La Sala Superior del TEPJF y el artículo 38, fracción II, constitucional (SUP-JDC-85/2007)}

Como ya se adelantó, fue al Tribunal Electoral a quien le correspondió conocer el asunto del que derivó el primer criterio que, a la postre, generaría la contradicción que aquí se analiza y cuyos datos más relevantes, para su adecuada comprensión, son los siguientes:

\section{Antecedentes}

El 11 de diciembre de 2006, un ciudadano ${ }^{6}$ acudió al módulo de atención ciudadana del IFE, a efecto de iniciar el trámite de inscripción al padrón electoral, acusándosele el recibo procedente.

El 19 de enero de 2007 fue a recoger su credencial de elector, pero no la obtuvo porque se le informó la no procedencia del trámite derivado de su situación judicial, al encontrarse suspendido en sus derechos político-electorales.

Al no recibir su credencial para votar con fotografía, el interesado promovió ante el módulo de referencia, la solicitud de expedición de credencial para votar con fotografía, a la cual le fue asignado el número de folio correspondiente.

El 16 de febrero de 2007, el vocal del Registro Federal de Electores emitió resolución respecto del expediente integrado con motivo de la solicitud de expedición de credencial para votar con fotografía, en los términos siguientes:

... II. La Solicitud de Expedición de Credencial Para Votar presentada por ${ }^{* * *}$, es IMPROCEDENTE en razón de las siguientes consideraciones:

En los archivos de la Dirección Ejecutiva del Registro Federal de Electores existe información proporcionada por el Juez Penal de Libres en la que se señala que se dictó en su contra auto de formal prisión en la causa penal ${ }^{\star * \star}$, por lo que fue suspendido de sus derechos políticos conforme a lo dispuesto en el artículo 38 Constitucional.

6 Se resguarda el nombre del ciudadano-actor, por tratarse de información confidencial en términos de los artículos 3o., fracción II; 4o., fracción III, y 18, fracción II, de la Ley Federal de Transparencia y Acceso a la Información Pública Gubernamental. 
Se dejan a salvo sus Derechos para hacerlos valer a través de la Demanda de Juicio para la Protección de los Derechos Político- Electorales del ciudadano, prevista por los artículos 151, párrafo 6, del ordenamiento legal citado, en relación con los artículos 79, 80 párrafo 1, inciso a), 81 y demás relativos y aplicables de la Ley General del Sistema de Medios de Impugnación en Materia Electoral...

En la misma fecha, a través del formato correspondiente puesto a su disposición por la propia autoridad, el ciudadano promovió un juicio para la protección de los derechos político electorales del ciudadano.

Todo lo anterior se ajustó al procedimiento que para solicitar el registro en el padrón electoral y obtener la credencial para votar se encuentra previsto en el artículo 151 del Código Federal de Instituciones y Procedimientos Electorales (Cofipe) que se encontraba vigente en aquél momento, ${ }^{7}$ cuyo texto se encuentra recuperado en el

\section{7 "Artículo 151}

1. Podrán solicitar la expedición de credencial para votar con fotografía o la rectificación ante la oficina del Instituto Federal Electoral responsable de la inscripción, aquellos ciudadanos que:

a) Habiendo cumplido con los requisitos y trámites correspondientes no hubieren obtenido oportunamente su credencial para votar con fotografía;

b) Habiendo obtenido oportunamente su credencial para votar con fotografía, no aparezcan incluidos en la lista nominal de electores de la sección correspondiente a su domicilio; o

c) Consideren haber sido indebidamente excluidos de la lista nominal de electores de la sección correspondiente a su domicilio.

2. En los casos a que se refiere el párrafo anterior, la solicitud de expedición o de rectificación se presentará en cualquier tiempo durante los dos años previos al del proceso electoral.

3. En el año de la elección los ciudadanos que se encuentren en el supuesto del inciso a) del párrafo 1 de este artículo, podrán promover la instancia administrativa correspondiente para obtener su credencial para votar con fotografía hasta el día último de febrero. En los casos previstos en los incisos b) y c) del párrafo señalado, los ciudadanos podrán presentar solicitud de rectificación a más tardar el día 14 de abril.

4. En las oficinas del Registro Federal de Electores, existirán a disposición de los ciudadanos los formatos necesarios para la presentación de la solicitud respectiva.

5. La oficina ante la que se haya solicitado la expedición de credencial o la rectificación resolverá sobre la procedencia o improcedencia de la misma dentro de un plazo de veinte días naturales.

6. La resolución que declare improcedente la instancia administrativa para obtener la credencial o de rectificación o la falta de respuesta en tiempo, serán impugnables ante el Tribunal Electoral. Para tal efecto, los ciudadanos interesados tendrán a su disposición 
numeral 187 del código federal electoral vigente. ${ }^{8}$

Una vez tramitada la demanda, el 20 de febrero de 2007, se remitió a la Sala Superior del TEPJF el expediente formado con motivo del juicio señalado y el informe circunstanciado. Sumario sobre el que, previo registro y sustanciación, se formuló el proyecto de sentencia correspondiente.

\section{Resumen de la sentencia}

En sesión pública, la Sala Superior del TEPJF por unanimidad de votos, al considerar que se violó el derecho del actor a contar con su credencial para votar con fotografía, resolvió revocar la negativa que dictó la Vocalía en la 06 Junta Distrital Ejecutiva en el estado de Puebla perteneciente a la Dirección Ejecutiva del Registro Federal de Electores del IFE.

De igual modo, ordenó a la citada autoridad que lo reincorporara en el padrón electoral y listado nominal correspondiente a su domicilio y que expidiera su credencial para votar con fotografía, a fin de que no se le vulnerara su derecho al sufragio, ${ }^{9}$ para lo cual otorgó un plazo de 15 días naturales y le ordenó que le informara sobre el cumplimiento a lo ahí ordenado.

Resulta importante señalar que en dicha sentencia también se estableció que, en caso de dictarse sentencia condenatoria privativa de la libertad y como consecuencia de ello se suspendieran los derechos político electorales del sentenciado, el juez de la causa, atendiendo a lo previsto en el artículo 162, párrafo 3, del Cofipe entonces vigente, ${ }^{10}$ debería de inmediato comunicarlo al IFE para que, por conducto del Registro Federal de Electores, procediera a darlo de baja del Padrón Electoral y del listado nominal correspondiente a su domicilio.

en las oficinas del Registro Federal de Electores los formatos necesarios para la interposición del medio de impugnación respectivo.

7. La resolución recaída a la instancia administrativa para obtener la credencial o de rectificación, será notificada personalmente al ciudadano si éste comparece ante la oficina responsable de la inscripción o, en su caso, por telegrama o correo certificado".

8 Publicado en el Diario Oficial de la Federación del 14 de enero de 2008.

9 Cabe recordar que en el estado de Puebla, en 2007 se celebraron las elecciones de diputados locales e integrantes de los Ayuntamientos.

10 Hoy es el artículo 198, párrafo 3, del Cofipe. 
Las consideraciones que soportaron esas determinaciones, pueden resumirse en los términos siguientes:

\section{A. Agravio}

Tomando en cuenta que el actor formuló su demanda de juicio ciudadano en el formato que para tal efecto le proporcionó la autoridad que le negó su registro y credencial de elector, en cuyo apartado de agravio sólo se contenía que se "le impide su derecho a votar que la CPEUM le otorga como ciudadano mexicano". La Sala Superior determinó, en suplencia, ${ }^{11}$ que de toda la demanda era posible concluir, que la lesión consistía en el impedimento para emitir en su oportunidad el sufragio en los comicios locales que tendrían verificativo en el estado de Puebla en noviembre, para lo cual las Constituciones federal y estatal así como el código electoral de la entidad, requerían para el ejercicio del derecho al voto, estar inscrito en el Registro Federal de Electores y contar con credencial para votar con fotografía.

\section{B. Estudio de fondo}

Se consideró que si bien quedaba acreditada la situación judicial invocada por la autoridad responsable cuyo sustento era el artículo 38, fracción II, de la Constitución federal, lo cierto era que la misma ley fundamental establecía una serie de bases para admitir que tal suspensión no era absoluta ni categórica.

Ello, teniendo en cuenta lo previsto en el artículo 133 constitucional y su correspondiente interpretación, ${ }^{12}$ en el sentido de que si los instrumentos internacionales amplían los derechos y prerrogativas previstos en la Constitución, entonces deben considerarse como normas supremas de la Unión y constitucionalmente válidas y, por consecuencia, obligan al Estado a velar y respetar en todo momento los derechos humanos ahí reconocidos.

11 Artículo 23, párrafos 1 y 3, de la Ley General del Sistema de Medios de Impugnación en Materia Electoral.

12 Según la tesis aislada de la SCJN de clave P.IX/2007 y rubro: Tratados INTERNACIONALES. SON PARTE INTEGRANTE DE LA LEY SUPREMA DE LA UNIÓN Y SE UBICAN JERÁRQUiCAMENTE POR ENCIMA DE LAS LEYES GENERALES, FEDERALES Y LOCALES, INTERPRETACIÓN DEL ARTÍCULO 133 CONSTITUCIONAL. 
Bajo esa premisa, se consideró que del alcance normativo del artículo 25 del Pacto de Derechos Civiles y Políticos que fijó el Comité de Derechos Civiles y Políticos de la Organización de Naciones Unidas, ${ }^{13}$ era posible concluir que al estar sujeto a proceso y no encontrarse privado de la libertad, debía permitírsele ejercer el derecho a votar y, por tanto, a contar con su credencial para votar.

Para sustentar esa conclusión, en una primera etapa de la ejecutoria se examina el arco jurídico aplicable, sobre las tres premisas siguientes:

i) Presunción de inocencia. En el caso se explicó que, la SCJN ha reconocido ${ }^{14}$ que en los artículos 14, párrafo segundo; 16, párrafo primero; 19, párrafo primero; 21, párrafo primero, y 102, apartado A, párrafo segundo, de la CPEUM, subyace el aludido principio que esencialmente consiste en que toda persona a quien se le imputa un delito tiene derecho a ser considerada inocente, mientras no se pruebe legalmente su culpabilidad en un proceso seguido con todas las garantías previstas por la ley, donde se establezca la responsabilidad a través de una declaración judicial de condena firme.

Por un lado, se razonó, ello protege al acusado frente a los excesos, las desviaciones y las perversiones en la acusación y, por otra parte, garantiza la libertad personal física o de tránsito de los individuos.

Se sigue explicando que dicho principio ha sido reconocido expresamente por el Estado mexicano, en los artículos 11, párrafo 1, de la Declaración Universal de los Derechos Humanos; XXVI de la Declaración Americana de los Derechos y Deberes del Hombre; 14, párrafo 2, del Pacto Internacional de Derechos Civiles y Políticos; así como 7o., párrafo 5, y 8o., párrafo 2, de la Convención Americana sobre Derechos Humanos.

Por consiguiente, se expuso que la interpretación armónica, sistemática y funcional del artículo 38, fracción II, constitucional, en relación con todas las disposiciones jurídicas antes enumeradas que prevén el principio de presunción de inocencia, permitía concluir que aun cuando el entonces actor estuviera sujeto a la traba de la formal prisión por su presunta responsabilidad en la comisión de los ilícitos, no había

13 En la observación general número 25 de su 57 periodo de sesiones de 1996, cuyo texto en lo que interesa dice: "A las personas a quienes se prive de la libertad pero que no hayan sido condenadas no se les debe impedir que ejerzan su derecho a votar".

14 Tesis aislada P. XXXV/2002, de rubro Presunción DE inocencia. El PRincipio RELATIVO SE CONTIENE DE MANERA IMPLÍCITA EN LA CONSTITUCIÓN FEDERAL. 
sido condenado, lo cual se estimó es condición para ser suspendido en el derecho a votar.

Para robustecer lo anterior, se razonó que si la presunción de inocencia se suma a que el sujeto a proceso penal, lo enfrenta en libertad por haber obtenido el beneficio constitucional previsto en el artículo 20, párrafo primero, entonces no existen razones válidas para justificar la suspensión del derecho a votar, ya que no estaría impedido físicamente para ejercer, entre otros, los derechos y prerrogativas constitucionales en estudio.

ii) El derecho a intervenir en los asuntos públicos y la correspondiente obligación a respetar el orden público. La ejecutoria en comento, también toma en consideración que el derecho que tienen los ciudadanos de participar en la toma de decisiones de los asuntos públicos, conlleva el deber de respetar el orden público. Por tanto, se razona que, es objetivo y razonable que se reconozcan casos en donde el incumplimiento de ese deber justifica que el ciudadano sea restringido transitoriamente del ejercicio de las prerrogativas que le otorga esa condición, tal como sucede cuando se dicta una sentencia ejecutoria que lo declare responsable del delito que tenga prevista una pena privativa de la libertad.

iii) Legislación penal del estado de Puebla. Se razonó que de los artículos 50 y 220, fracciones I y II, del Código de Procedimientos en Materia de Defensa Social, es posible concluir que el auto de formal prisión podrá tener algunas de las consecuencias siguientes: $a$ ) señalar el delito o delitos por los que se ha de seguir el proceso; $b$ ) inicia el periodo del proceso formal a que se refiere el artículo 20, fracción VIII, de la Constitución general; c) justifica la prisión del sujeto activo, convirtiéndose el indiciado en procesado, $\mathrm{y} d$ ) suspende los derechos $\mathrm{y}$ prerrogativas del ciudadano, en términos de la fracción II del artículo 38 multicitado.

A continuación, en la sentencia se describe el caso particular, en donde se destacaron como otros datos relevantes, los siguientes:

1) El 29 de marzo y 4 de diciembre de 2005, el juez mixto del Distrito Judicial de San Juan de los Llanos Libres, Puebla, dentro del proceso penal número 30/2005, dictó diversos autos de formal prisión en contra del ciudadano, como presunto responsable de diferentes delitos de carácter culposo. 
2) Mediante notificación del Poder Judicial del Estado de Puebla al área de depuración al padrón de la Vocalía del Registro Federal de Electores, el juez de San Juan de los Llanos Libres, Puebla, informó de un primer auto de formal prisión dictado en contra del por la comisión de varios ilícitos.

3) El 16 de febrero de 2007, como ya se anticipó, el vocal del Registro Federal de Electores dictó la resolución respecto a la solicitud de expedición de credencial de elector, en el sentido de que su trámite resultaba improcedente derivado de su situación jurídica.

4) En razón del requerimiento formulado por la magistrada electoral instructora al juez de la causa, éste informó que los autos se encontraban en estado de dictar sentencia.

Con base en lo anterior, en la sentencia de la Sala Superior del TEPJF se razona que al ciudadano, de conformidad con lo dispuesto en los numerales 305, 307, 312, 414, fracción IV en relación con el 83 del Código de Defensa Social para el Estado de Puebla, le fue iniciado proceso penal por su presunta responsabilidad en la comisión de diversos delitos de carácter culposo, por lo que, al haberse acreditado el cuerpo del delito y su presunta responsabilidad en los hechos imputados, le fueron dictados sendos autos de formal prisión. No obstante, al tratarse de delitos catalogados como no graves y satisfacer además las exigencias que dispone el Código de Defensa Social aludido, le fue concedida la libertad bajo fianza, para seguir fuera de prisión el procedimiento instaurado en su contra.

Para terminar la descripción del mencionado caso, se señaló que tampoco existía controversia sobre que desde el primer auto de formal prisión, por instrucciones de la autoridad judicial, al entonces actor se le suspendieron sus derechos políticos por conducto del IFE, conforme a lo dispuesto por la fracción II del artículo 38 de la CPEUM.

Ahora bien, en la sentencia de la Sala Superior, para llevar a cabo la subsunción, se comienza reconociendo que la interpretación gramatical del dispositivo en mención permitiría estimar, que al encontrarse sub judice la causa penal instaurada en contra del actor, éste fue dado de baja correctamente del padrón electoral y, como consecuencia, la negativa impugnada sería legal, hasta en tanto cesaran las causas que provocaron la limitación a sus derechos. ${ }^{15}$ Lo anterior, tomando en

${ }^{15}$ Lo cual podría acontecer con el dictado de la sentencia absolutoria, el cumplimiento de la sentencia condenatoria o si se acoge a alguno de los beneficios sustitutivos de las penas. 
consideración que, cuando la pena de prisión se extingue, la suspensión de derechos políticos, al ser una pena accesoria también se extingue, salvo en el supuesto previsto en la fracción VI del artículo 38 constitucional.

Sin embargo, se consideró que la interpretación garantista, sistemática y funcional del precepto constitucional que establece la mencionada causa de suspensión de derechos, lleva a la convicción que ésta sólo debe operar cuando se obligue irremediablemente al procesado, al no existir una alternativa legal para ello, a ser privado físicamente de su libertad.

Como consecuencia, se razona que quedan automáticamente fuera de dicha sujeción los delitos que no necesariamente se castigan con pena privativa de libertad, como los que sólo se castigan con sanción pecuniaria, apercibimiento o pena alternativa, invocándose como un criterio orientador la jurisprudencia de rubro: DeReChos políticos. Suspensión de. El artículo 46 del Código Penal Federal amPLÍA LA GARANTÍA CONSTITUCIONAL QUE PREVÉ LA FRACCIÓN II DEL ordinal 38 DE LA Constitución Política de los Estados Unidos Mexicanos. ${ }^{16}$

Además, se apunta que al ser nuestro país una federación, los estados de la República cuentan con atribuciones para regular los requisitos que deben colmarse para que las personas puedan ser consideradas como ciudadanos de la entidad, sus derechos y prerrogativas así como las causas por las cuales se suspenden éstos.

De ello se sigue, dice la sentencia, que resulte válido que el artículo 24 de la Constitución Política del Estado de Puebla regule las causas de suspensión de los derechos y prerrogativas de los ciudadanos poblanos, en cuya fracción III la condiciona a aquellos ciudadanos que presuntamente hubieran cometido un delito intencional, entendiendo este último, cuando el agente realiza consciente y voluntariamente la acción u omisión socialmente peligrosa y ha querido su resultado.

En ese orden de ideas, se razonó que al entonces actor se le consideró en los autos de formal prisión como responsable de diferentes delitos de carácter culposo, en otras palabras, por conductas imprudentes o negligentes que ocasionan un evento dañino o peligroso previsto por la ley como delito, cuyo resultado es involuntario.

${ }^{16}$ Emitida por el Décimo Tribunal Colegiado en Materia Penal del Primer Circuito, consultable en Semanario Judicial de la Federación y su Gaceta, Novena Época, mayo de 2006, t. XXIII, p. 191. 
Por tanto, se consideró que no se encontraba suspendido en sus derechos y prerrogativas y, por ende, tenía expedito el derecho a votar en las elecciones del estado de Puebla de dicho año, debiendo contar para ello, con la correspondiente inscripción en el Registro Federal de Electores así como con la credencial para votar con fotografía, en términos del convenio de colaboración que se había celebrado entre el IFE y el Instituto Electoral del Estado de Puebla para el desarrollo de los comicios que tendrían verificativo en $2007 .{ }^{17}$

Al respecto, se reconoció que la Constitución del estado de Puebla, en el mencionado artículo 24, fracción III, resulta más protectora o benéfica que lo previsto en el artículo 38, fracción II, de la Constitución Federal, en congruencia con el mencionado principio de presunción de inocencia.

Por último, se tomó en cuenta que no era factible considerar que las prerrogativas del ciudadano puedan ser fraccionadas, por lo que al continuar, con base en el citado dispositivo constitucional local, como ciudadano del estado de Puebla, el efecto tenía que ser su reconocimiento como tal en cualquier ámbito (federal o local) y la posibilidad de votar, no obstante encontrarse sujeto a un proceso penal.

\section{Conclusiones de la ejecutoria}

Invocándose la obligación del Estado mexicano de respetar los derechos humanos, entre los cuales se encuentran los de tipo políticoelectoral, se recordó que contrajo también la obligación específica de adoptar todas las medidas o disposiciones legislativas o de cualquier carácter necesarias para dar vigencia y efectividad a tales derechos y libertades, entre las cuales se encuentra toda interpretación y la correlativa aplicación de una norma jurídica que amplíe y potencie su ejercicio.

Por tanto, la interpretación y aplicación de una norma aun de carácter constitucional que limite los derechos humanos, debe ser realizada restrictivamente, rigiéndose por el principio favor libertatis que obliga a los órganos del Estado a accionar a favor del mayor grado de ejercicio posible del derecho humano de que se trate, como se sostuvo en la jurisprudencia de la Sala Superior de rubro Derechos fUndA-

17 Publicado en el Periódico Oficial del Estado de Puebla el 28 de mayo de 2007. 
MENTALES DE CARÁCTER POLÍTICO-ELECTORAL. Su INTERPRETACiÓN Y CORRELATIVA APLICACIÓN NO DEBE SER RESTRICTIVA. ${ }^{18}$

\section{Efectos de la ejecutoria}

Con base en todo lo explicado, se determinó revocar la resolución combatida y, por ende, ordenarle a la Dirección Ejecutiva del Registro Federal de Electores, por conducto de su Vocalía en la 06 Junta Distrital Ejecutiva en el Estado de Puebla: ${ }^{19}$ 1) lo reincorporara en el Padrón Electoral; 2) le expidiera su credencial para votar con fotografía, y 3) lo inscribiera a la lista nominal de electores correspondiente a su domicilio.

Para cumplimentar lo anterior y frente a la posibilidad de que cambiara la situación jurídica del entonces actor, la Sala Superior estableció en la propia sentencia que se explica, distintos lineamientos de los cuales ya no nos ocuparemos por distraernos del objeto esencial de este trabajo.

\section{Emisión de la tesis XV/2007}

Producto del criterio sustentado en la sentencia que recayó al juicio ciudadano identificado con la clave SUP-JDC-85/2007, la Sala Superior del TEPJF en sesión pública celebrada el 21 de septiembre de 2007, aprobó por unanimidad de 6 votos, ${ }^{20}$ la tesis de rubro y texto siguientes:

SUSPENSIÓN DE LOS DERECHOS POLÍTICO-ELECTORALES DEL CIUDADANO PREVISTA EN LA FRACCión II DEL ARTí́culo 38 CONSTITUCiONAL. Sólo PROCEDE CUANDO SE PRIVE DE LA LIBERTAD.- La interpretación armó-

18 Cuya clave es S3ELJ 029/2002. Actualmente visible en la Compilación 1997-2010 Jurisprudencia y tesis en materia electoral, Jurisprudencia vol. 1, pp. 254-256, publicada por el TEPJF.

19 Quedaron vinculados a partir de lo previsto en la jurisprudencia 30/2002 emitida por la Sala Superior del TEPJF de rubro Dirección Ejecutiva del Registro Federal DE Electores. Los vocales Respectivos SON CONSIDERADOS COMO RESPONSABLES DE LA NO EXPEDICIÓN DE LA CREDENCIAL PARA VOTAR CON FOTOGRAFÍA, AUNQUE NO SE Les MENCIONE EN El ESCRito De Demanda. Actualmente consultable en la Compilación 1997-2010 Jurisprudencia y tesis en materia electoral, Jurisprudencia vol. 1, pp. 272 y 273 , publicada por el TEPJF.

${ }^{20}$ Se encontró ausente el magistrado Manuel González Oropeza. 
nica, sistemática y funcional del artículo 38, fracción II, en relación con los artículos 14, 16, 19, 21 y 102, de la Constitución Política de los Estados Unidos Mexicanos; 14, párrafo 2 y 25 del Pacto Internacional de Derechos Civiles y Políticos; 11, párrafo 1 de la Declaración Universal de los Derechos Humanos; 26 de la Declaración Americana de los Derechos y Deberes del Hombre; 7, párrafo 5, y 8 de la Convención Americana sobre Derechos Humanos, permite concluir que la suspensión de los derechos o prerrogativas del ciudadano por estar sujeto a un proceso criminal por delito que merezca pena corporal, a contar desde la fecha del auto de formal prisión no es absoluta ni categórica. En efecto, las referidas disposiciones establecen las bases para admitir que, aun cuando el ciudadano haya sido sujeto a proceso penal, al habérsele otorgado la libertad caucional y materialmente no se le hubiere recluido a prisión, no hay razones válidas para justificar la suspensión de sus derechos político-electorales; pues resulta innegable que, salvo la limitación referida, al no haberse privado la libertad personal del sujeto y al operar en su favor la presunción de inocencia, debe continuar con el uso y goce de sus derechos. Por lo anterior, congruentes con la presunción de inocencia reconocida en la Constitución Federal como derecho fundamental y recogida en los citados instrumentos internacionales, aprobados y ratificados en términos del artículo 133 de la Constitución Política de los Estados Unidos Mexicanos, la suspensión de derechos consistente en la restricción particular y transitoria del ejercicio de los derechos del ciudadano relativos a la participación política, debe basarse en criterios objetivos y razonables. Por tanto, tal situación resulta suficiente para considerar que, mientras no se le prive de la libertad y, por ende, se le impida el ejercicio de sus derechos y prerrogativas constitucionales, tampoco hay razones que justifiquen la suspensión o merma en el derecho político-electoral de votar del ciudadano.

\section{La Primera Sala de la SCJN y el artículo 38, fracción II, constitucional (contradicción de tesis 29/2007)}

Muy poco tiempo después, el 31 de octubre de 2007, la Primera Sala de la SCJN dictó resolución en la contradicción de tesis 29/2007-PS. ${ }^{21}$

${ }^{21}$ Entre las sustentadas por el Primer Tribunal Colegiado en Materias Penal y Administrativa del Quinto Circuito y los Tribunales Colegiados Décimo y Sexto, ambos en Materia Penal del Primer Circuito. 
La lectura de dicha resolución permite advertir que el examen que se realizó, incluyó todas las hipótesis de suspensión de derechos políticos previstas en las fracciones II a VI del artículo 38 constitucional. Por tanto, para efectos de este trabajo, a continuación se presentan lo que desde nuestra perspectiva son, los puntos medulares de su criterio, en lo que se refiere a la fracción II del artículo 38 constitucional, procurando evitar su descontextualización.

La Primera Sala de la SCJN dijo en su sentencia, que los artículos 35 y 38 de la CPEUM integran una unidad sistemática y particularmente fundamental, como base de las instituciones políticas, lo que da razón de su estructura jurídica y de la finalidad política del ejercicio de ese poder soberano que ejerce o debe ejercerse, en el interés general de la nación mexicana.

Precisó que la suspensión de los derechos o prerrogativas de los ciudadanos constituye una privación temporal de los que les corresponde a esa categoría política, durante el tiempo que la ley establece, y los ciudadanos suspensos en sus derechos quedan excluidos del electorado, esto es, de la posibilidad de ser elegidos y de participar en la organización política.

Respecto a la fracción II del artículo 38 citado, dice que la sujeción a un proceso penal por delito que merezca pena corporal, es causa de suspensión de los derechos políticos del ciudadano; que el plazo de la misma empezará a computarse a partir de la fecha del auto de formal prisión, por lo que atendiendo a lo dispuesto en la referida fracción, debe interpretarse que esta causa de suspensión de derechos políticos tiene efectos únicamente durante el proceso penal, es decir, desde la fecha del auto de formal prisión, hasta que se pronuncie la sentencia absolutoria en el proceso respectivo, pero si la resolución es condenatoria, la situación pasa a regirse conforme a lo previsto en la fracción III del citado precepto constitucional, esto es, la suspensión se prolongaría durante el tiempo de la extinción de la pena corporal que se le imponga.

Aclara que no debe confundirse la suspensión de los derechos políticos que se concretiza con el dictado del auto de formal prisión con base en el artículo 38, fracción II, constitucional, al estar sujeto a un proceso criminal que merezca pena corporal, con las diversas suspensiones que como pena contempla el mismo dispositivo, pero en sus fracciones III a VI, respectivamente, cuya naturaleza jurídica, y aquí 
hace un especial énfasis, es diversa a lo previsto en los artículos 45 y 46 del Código Penal Federal. ${ }^{22}$

Sobre este particular, explica que el contenido del artículo $46 \mathrm{del}$ código en cita, no puede ser considerado como ampliación alguna de la garantía constitucional respecto de la suspensión de derechos políticos con motivo del dictado del auto de formal prisión, tomando en cuenta el sustento que el Constituyente de 1917 dio al artículo 38, fracción II.

De ahí, considera que no existe confrontación alguna de normas entre lo dispuesto por ese precepto constitucional con lo establecido en el artículo 46 del Código Penal Federal, pues este último es acorde con lo dispuesto en la fracción III del artículo 38 constitucional, lo que no implica que exista un conflicto de normas que deba resolverse conforme al principio de la ley más favorable al quejoso, debido a que no se actualiza contradicción alguna entre ambos preceptos.

Refiere en este punto, que en la ciudadanía reside el fundamento jurídico de los derechos políticos, y que se trata de una capacidad de la que deriva la aptitud para ser titular de ellos, constituyendo un estatus jurídico que incluye facultades pero también impone obligaciones que serán la base para determinar la procedencia de la suspensión de las prerrogativas relacionadas con esta condición.

Precisado lo anterior, explica que el artículo 38 contempla tres causas distintas que pueden provocar la suspensión de derechos políticos, diciendo respecto de la fracción II, que la misma podría conceptuarse como una consecuencia accesoria de la sujeción a proceso y no como pena, sanción o medida cautelar, pues su naturaleza y finalidad no responden a la de estos últimos conceptos.

Una vez explicadas las tres hipótesis del artículo 38, la Primera Sala señala que pueden ser reguladas por los códigos punitivos locales y

22 Artículo 45.- La suspensión de derechos es de dos clases: I.- La que por ministerio de la ley resulta de una sanción como consecuencia necesaria de ésta, y II.- La que por sentencia formal se impone como sanción. En el primer caso, la suspensión comienza y concluye con la sanción de que es consecuencia. En el segundo caso, si la suspensión se impone con otra sanción privativa de libertad, comenzará al terminar ésta y su duración será la señalada en la sentencia.

Artículo 46.- La pena de prisión produce la suspensión de los derechos políticos y los de tutela, curatela, ser apoderado, defensor, albacea, perito, depositario o interventor judicial, síndico o interventor en quiebras, árbitro, arbitrador o representante de ausentes. La suspensión comenzará desde que cause ejecutoria la sentencia respectiva y durará todo el tiempo de la condena. 
federal en la forma que el legislador ordinario considere conveniente, tal como lo establece el párrafo final del citado precepto constitucional, pero en ningún caso podrán oponerse a la norma constitucional $\mathrm{y}$, por lo tanto, su aplicación es preferente respecto a cualquier otra disposición que pudiera contradecirla. Lo anterior, en acatamiento al principio de supremacía constitucional, ya que si se considera a la suspensión de derechos como consecuencia accesoria de la privación de libertad por estar sujeto un ciudadano a proceso por delito que merezca pena corporal, es lógico que la suspensión tendrá efectos desde el dictado del auto de formal prisión, pues además de que así lo establece textualmente ese precepto y fracción de la ley fundamental y concluirá con la resolución definitiva que ponga fin al juicio, sea ésta absolutoria o condenatoria, pues a partir de este momento el ciudadano dejará de "estar sujeto a un proceso criminal" en términos de la fracción que se analiza.

Apunta, que la suspensión en comento, no es una garantía del suspenso que sea susceptible de ser ampliada, pues tiene una naturaleza jurídica distinta, en razón de la que opera como una privación temporal de las prerrogativas que corresponden a la categoría política durante el tiempo que dure el proceso penal, de modo que los suspensos en esos derechos queden excluidos del electorado y de la posibilidad de ser elegidos; esto es, de participar en la organización política nacional, sin que esto pueda ser ignorado o modificado por una ley secundaria, pues ello implicaría contradecir una restricción constitucional. Deriva de lo anterior que al igual que la prisión preventiva tiene sus motivos, la suspensión en examen tiene los propios, pues constituye de igual manera una medida de seguridad que no supone en forma alguna una sanción ni una consecuencia a una sanción, pues únicamente constituye una restricción constitucional de carácter provisional al ejercicio de un derecho, ello con finalidades precisas, en cuya atención no puede eliminarse por la legislación ordinaria.

Aclarado lo anterior, explica que no se reúnen los presupuestos del concurso aparente de normas, ya que para ello es necesario que la contienda se dé entre leyes del mismo nivel jerárquico, lo cual no es factible que ocurra entre la Constitución federal y una ley ordinaria, además de que se requiere que ambas normas regulen la misma conducta, hecho o supuesto, lo que no sucede entre el artículo 38, fracción II, constitucional, y el numeral 46 del Código Penal Federal, al regular este último lo previsto en las fracciones III a VI del referido artículo 38. 
Por tanto, consideró que es correcta la determinación de suspender los derechos políticos del ciudadano en términos de la fracción II del artículo 38 constitucional, desde el momento en que se dicta el auto de formal prisión por delito que merezca pena corporal, el cual al no tener prerrogativas, sino una restricción de éstas, no puede argumentarse que el numeral 46 del Código Penal Federal amplíe los derechos del inculpado.

Esto, dice la Primera Sala de la SCJN, obedece a que existe una diferencia de técnica procesal entre los momentos en que procede suspender los derechos de los ciudadanos, pues el primer momento se concretiza, acorde al artículo 38, fracción II, constitucional, en la etapa de preinstrucción, donde se dicta el auto de formal prisión, para dar paso a la diversa fase de instrucción, siendo claro que lo ahí decretado, entre otras cuestiones la suspensión de derechos, no se considera como pena, ya que lo decretado en el referido auto resulta ser una cuestión meramente provisional, ya que por una parte el juez al dictarlo, debe tener en cuenta los elementos que acrediten el cuerpo del delito y la probable responsabilidad del inculpado, en términos del artículo 19 de la ley suprema, pero sin que jurídicamente tenga la facultad de imponer sanción alguna.

Por ende, termina concluyendo, se guarda la independencia y autonomía con un diverso momento y distintas clases de suspensiones decretadas en otra etapa procesal al dictado de una sentencia condenatoria que cause ejecutoria, a saber, la suspensión impuesta según la fracción III del citado precepto constitucional, como resultado de una pena corporal o bien, porque tal suspensión se impuso como pena acorde con la fracción VI del precepto referido.

\section{Emisión de jurisprudencia}

Como consecuencia de la mencionada contradicción, la Primera Sala de la SCJN dictó por unanimidad de cinco votos la tesis de jurisprudencia 171/2007, en sesión del 28 de noviembre de 2007, que a la letra dice:

Derechos políticos. Deben declararse suspendidos desde el dicTADO DEL AUTO DE FORMAL PRISIÓN, EN TÉRMINOS DEL ARTíCUlo 38, fRacción iI, de la Constitución Política de los Estados Unidos 
Mexicanos. Si bien el citado precepto constitucional dispone expresa y categóricamente que los derechos o prerrogativas de los ciudadanos se suspenden a causa de un proceso criminal por delito que merezca pena corporal y que el plazo relativo se contará desde la fecha de la emisión del auto de formal prisión; y, por su parte, el artículo 46 del Código Penal Federal señala que la referida suspensión se impondrá como pena en la sentencia que culmine el proceso respectivo, que comenzará a computarse desde que cause ejecutoria y durará todo el tiempo de la condena - lo cual es acorde con la fracción III del propio artículo 38 constitucional-, ello no significa que la suspensión de los derechos políticos establecida en la Carta Magna haya sido objeto de una ampliación de garantías por parte del legislador ordinario en el código sustantivo de la materia, ni que exista contradicción o conflicto de normas, ya que se trata de dos etapas procesales diferentes. Consecuentemente, deben declararse suspendidos los derechos políticos del ciudadano desde el dictado del auto de formal prisión por un delito que merezca pena corporal, en términos del artículo 38, fracción II, de la Constitución Federal; máxime que al no contener éste prerrogativas sino una restricción de ellas, no es válido afirmar que el mencionado artículo 46 amplíe derechos del inculpado. Lo anterior es así, porque no debe confundirse la suspensión que se concretiza con la emisión de dicho auto con las diversas suspensiones que como pena prevé el numeral 46 aludido como consecuencia de la sentencia condenatoria que al efecto se dicte, entre las que se encuentra la de derechos políticos, pues mientras la primera tiene efectos temporales, es decir, sólo durante el proceso penal, los de la segunda son definitivos y se verifican durante el tiempo de extinción de la pena corporal impuesta. ${ }^{23}$

\section{La sentencia del pleno de la SCJN recaída a la contradicción de tesis 6/2008-PL}

El análisis de la contradicción cuyos componentes han quedado arriba descritos, fue examinado por el pleno de la SCJN en dos diversas sesiones, celebradas el 7 de enero de 2010 y el 26 de mayo de 2011.

${ }^{23}$ Semanario Judicial de la Federación y su Gaceta, Novena Época, t. XXVII, febrero de 2008, p. 215. 
Propuesta de quedar sin materia la contradicción tesis. En la correspondiente a enero de 2010, se planteó la posibilidad de que la mencionada contradicción se declarara sin materia, bajo la idea de que el pleno de la SCJN ya había interpretado lo dispuesto en el artículo 38, fracción II, constitucional, al resolver las acciones de inconstitucionalidad 33/2009 ${ }^{24}$ y sus acumuladas 34/2009 y 35/2009 en sesión del 28 de mayo de 2009, en la que se determinó que ese precepto contenía un restricción constitucional y que la sujeción a un proceso penal por delito que merezca pena corporal es causa de suspensión de los derechos políticos del ciudadano así como que la referida fracción debe interpretarse en el sentido de que la causa que prevé tiene efectos únicamente durante el proceso penal, es decir, desde la fecha del auto de formal prisión hasta que se pronuncie la sentencia absolutoria en el proceso respectivo.

Tal cuestión, en concepto del pleno de la SCJN, hizo necesario establecer los alcances de lo dispuesto en el artículo 43 de la Ley Reglamentaria de las fracciones I y II del artículo 105 de la CPEUM, en relación con los efectos que producen las sentencias de las acciones de inconstitucionalidad frente a la competencia del TEPJF.

Previo estudio del marco jurídico aplicable, determinó que la jurisprudencia emanada de las acciones de inconstitucionalidad en los términos del artículo 43 antes enunciado, también es obligatoria para el TEPJF, aunque ese órgano jurisdiccional no esté expresamente previsto en esa disposición, y es el medio de control que constituye la única vía para plantear la no conformidad de las leyes electorales a la Constitución, de acuerdo con lo establecido en el artículo 105, fracción II, párrafo tercero, constitucional.

${ }^{24}$ Promovidas por Convergencia, el Partido del Trabajo y el Partido de la Revolución Democrática, en contra del Decreto número 5, mediante el cual se modificaron los numerales 3, 4, 9 y 11 de la fracción III del artículo 27, el primer párrafo del artículo 33, el artículo 34, y la fracción VI del artículo 35 de la Constitución Política del Estado de Coahuila de Zaragoza, publicado en el Periódico Oficial del Gobierno Constitucional del Estado de Coahuila el 6 de febrero de 2009, así como el decreto número 6, que contiene el Código Electoral del Estado de Coahuila de Zaragoza, publicado en el mismo órgano oficial en la misma fecha, al considerarse violados los artículos 1o., 6o., 7o., 9o., 14, $16,17,20,21,34,35$, fracciones I y II; 36, fracciones III, IV y V; 38, 39, 40, 41, primer y segundo párrafo, fracción I, primer y segundo párrafos; 99; 115, párrafo primero, fracción I, párrafos primero y segundo; 116, segundo párrafo, fracción I, segundo párrafo, fracción II, párrafo primero, fracción IV; 128, 133 y 134 de la Constitución Política de los Estados Unidos Mexicanos. 
Esto, porque dijo que con base en una interpretación sistemática de los artículos 99 y 105, fracción II, constitucionales, y con apoyo en la naturaleza y las competencias establecidas por la propia Constitución federal, era de determinarse que la jurisprudencia de la SCJN mediante acciones de inconstitucionalidad, con base en los numerales 43 y 73 de la ley reglamentaria señalada con anterioridad, resulta obligatoria para el TEPJF.

Obligatoriedad, que dijo sostenerse también en el hecho de que la ley reglamentaria citada se publicó en el Diario Oficial de la Federación del 11 de mayo de 1995, mientras que el Tribunal Electoral del Poder Judicial de la Federación nació tiempo después con la reforma constitucional publicada en el mismo diario del 22 de agosto de 1996.

Aunado a que el artículo 235 de la Ley Orgánica del Poder Judicial de la Federación, ${ }^{25}$ en su opinión es claro en ordenar que la jurisprudencia del pleno de la SCJN será obligatoria para el TEPJF cuando se refiera a la interpretación directa de un precepto constitucional, y en los casos que resulte exactamente aplicable.

Lo anterior, sigue diciendo la sentencia que resolvió la contradicción, interpretado armónicamente con los numerales 43 y 73 de la ley reglamentaria mencionada confirma la obligatoriedad de las consideraciones que el pleno de la SCJN realice en las sentencias aprobadas por cuando menos 8 votos, dictadas en acciones de inconstitucionalidad.

Precisado lo anterior, al examinar la sentencia que recayó a las aludidas acciones de inconstitucionalidad determinó que las consideraciones ahí contenidas no daban respuesta exacta al punto jurídico a resolver en la citada contradicción, pues si bien en las mencionadas acciones de inconstitucionalidad se interpretó en forma abstracta y general la fracción II del artículo 38 constitucional, en términos similares a lo que estudió la Primera Sala en la ejecutoria materia de la contradicción y a la luz del principio de presunción de inocencia, también lo es que en el análisis que llevó a cabo ese pleno no se hizo referencia a la variable que correspondió estudiar al TEPJF, esto es, cómo opera la suspensión de derechos político electorales (concerniente al derecho a votar) cuando la persona sujeta a proceso se encuentra libre bajo

25 Artículo 235.- La jurisprudencia del Pleno de la Suprema Corte de Justicia de la Nación será obligatoria para el Tribunal Electoral, cuando se refiera a la interpretación directa de un precepto de la Constitución Política de los Estados Unidos Mexicanos, y en los casos en que resulte exactamente aplicable. 
caución, elemento que la condujo necesariamente a retomar el análisis constitucional de que se trata pero conforme a la variable apuntada.

De igual modo señaló, que tampoco podía considerarse que las razones que sustentaron los resolutivos de las mencionadas acciones de inconstitucionalidad constituían un precedente totalizador o absoluto, ni que contuvieran un pronunciamiento implícito sobre la cuestión planteada en la contradicción de tesis que se resolvía, toda vez que tratándose de un criterio que se traduce en una restricción de derechos fundamentales, ésta sólo puede quedar definida, dijo el pleno de la SCJN, por ese alto tribunal de forma explícita, en la inteligencia de que, en esa materia, debe ante todo privilegiarse el principio de seguridad jurídica de los titulares de los derechos fundamentales en juego, lo cual sólo puede conseguirse con la explicitud del criterio que define el alcance específico de dicha restricción.

Fijación de la contradicción. A la luz de los posicionamiento arriba descritos, el pleno de la SCJN determinó que sí existe la contradicción de tesis denunciada y que la materia de ésta consistía en determinar si el supuesto contenido en el artículo 38, fracción II, constitucional, que prevé la suspensión de los derechos o prerrogativas de los ciudadanos por estar sujeto a un proceso criminal por delito que merezca pena corporal, a contar desde la fecha del auto de formal prisión, tiene como consecuencia la suspensión del derecho a votar sin excepción alguna, o si dicha suspensión sólo se produce cuando existe privación de la libertad.

Resolución de la contradicción de tesis. El pleno de la SCJN retomó el presente caso en la sesión del 26 de mayo de 2011, y resolvió que el criterio que debía prevalecer, con carácter de jurisprudencia, en términos del artículo 99, párrafo séptimo, ${ }^{26}$ de la Constitución federal, que para efectos de este trabajo se subtitula por la que esto escribe, sería el siguiente:

26 Artículo 99, párrafo séptimo, de la CPEUM: "Cuando una sala del Tribunal Electoral sustente una tesis sobre la inconstitucionalidad de algún acto o resolución o sobre la interpretación de un precepto de esta Constitución, y dicha tesis pueda ser contradictoria con una sostenida por las salas o el Pleno de la Suprema Corte de Justicia, cualquiera de los Ministros, las salas o las partes, podrán denunciar la contradicción en los términos que señale la ley, para que el pleno de la Suprema Corte de Justicia de la Nación decida en definitiva cuál tesis debe prevalecer. Las resoluciones que se dicten en este supuesto no afectarán los asuntos ya resueltos". 
Cuestiones preliminares. Para iniciar, y teniendo a la vista los ámbitos de regulación de los artículos 35 y 38, fracción II, de la Constitución federal, explicó que si bien el último precepto mencionado hace referencia expresa al "auto de formal prisión" que no le pasaba inadvertido que mediante decreto publicado en el Diario Oficial de la Federación el 18 de junio de 2008, se reformó, entre otros, el artículo 19 de la CPEUM, en donde se hace referencia al "auto de vinculación a proceso", cuya entrada en vigor se sujetó a lo previsto en el artículo Segundo transitorio del mencionado decreto.

Por ende, aclaró que en la resolución de la contradicción se referiría al "auto de formal prisión", por ser el término utilizado por el artículo 38 , fracción II, constitucional.

Inmediatamente después, explicó que el citado precepto constitucional, desde su redacción original por el Constituyente de 1917 no ha sido objeto de reforma alguna.

Explicado lo anterior, las premisas sobre las cuales sostiene su criterio, son:

Presunción de inocencia. Razonó que en los artículos 14, párrafo segundo; 16, párrafo primero; 19 , párrafo primero; 21, párrafo primero, y 102, apartado A, párrafo segundo, de la Constitución federal, se prevé implícitamente el principio de presunción de inocencia como lo estableció el pleno de esa SCJN en la tesis PRESUNCión DE INOCENCIA. EL PRINCIPIO RELATIVO SE CONTIENE DE MANERA IMPLÍCITA EN LA CONSTITUCIÓN FEDERAL. ${ }^{27}$

Al examinar la parte conducente de la ejecutoria que dio sustento a dicha tesis, el pleno de la SCJN razonó que los principios constitucionales del debido proceso legal y el acusatorio resguardan en forma implícita el principio de presunción de inocencia, dando lugar a que el gobernado no esté obligado a probar la licitud de su conducta cuando se le imputa la comisión de un delito, al disponer expresamente que es al Ministerio Público a quien incumbe probar los elementos constitutivos del delito y de la culpabilidad del imputado.

Sumó a lo anterior, que ese tribunal pleno ha considerado que la presunción de inocencia que en materia procesal impone la obligación de arrojar la carga de la prueba al acusador, es un derecho fundamental cuyo alcance trasciende la órbita del debido proceso, pues con su

${ }_{27}$ Tesis P. XXXV/2002 derivada de resolver por unanimidad de votos el Amparo en Revisión 1293/2002. 
aplicación se garantiza la protección de otros derechos fundamentales como son la dignidad humana, al libertad, la honra y el buen nombre, que podrían resultar vulnerados por actuaciones penales o disciplinarias irregulares.

Incluso, destacó que la interpretación constitucional del referido principio que ese pleno ha fijado, ha servido de base para subrayar su existencia en el orden jurídico mexicano y para orientar la resolución de diversos asuntos que han sido del conocimiento de las salas de la SCJN para lo cual invocó diversas tesis ${ }^{28}$ de cuyos textos destacó los apartados en los que sustentó su estudio.

Tratados internacionales. Para robustecer su criterio, señaló que el principio apuntado también está reconocido en diversos instrumentos internacionales de los cuales México es parte, como la Declaración Universal de los Derechos Humanos, la Convención Americana sobre Derechos Humanos y el Pacto Internacional de Derechos Civiles y Políticos.

Sistema procesal penal acusatorio. Incluso, señaló que el nuevo sistema previsto en los artículos 16, párrafos segundo y décimo tercero; 17, párrafos tercero, cuarto y sexto; 19, 20 y 21, párrafo séptimo, de la CPEUM, que entrará en vigor cuando lo establezca la legislación secundaria, sin exceder el plazo de 8 años, contado a partir del día siguiente al de la publicación del decreto respectivo en términos de su artículo segundo transitorio (Diario Oficial de la Federación del 18 de junio de 2008), en el artículo 20, apartado B, fracción I, se establece expresamente el principio de presunción de inocencia.

Técnica y herramientas de interpretación que utilizaría. Consideró que ese pleno de la SCJN estaba obligado a hacer una interpretación armónica y sistemática del artículo 38, fracción II, de la CPEUM, en relación con el principio en cita reconocido por la ley fundamental.

En ese contexto explicó que acudir a una técnica de interpretación constitucional contemporánea que sostiene que entre la esfera de derechos fundamentales no existen contradicciones ni conflictos, sino

${ }^{28}$ Las tesis mencionadas fueron: "Prueba PRESUnCiOnAL. EN LA INVESTIGACión DE VIOLACIONES GRAVES DE GARANTÍAS INDIVIDUALES ESTABLECIDA EN EL ARTÍCULO 97, PÁRRAFo SEgUNDO, CONSTITUCIONAL"; "PRINCIPIO IN DUBIO PRO REO ESTÁ PREVISTO implícitamente en la Constitución Política de los Estados Unidos Mexicanos”; "Dolo. Carga de la prueba de su acreditamiento"; "Causa de exclusión del

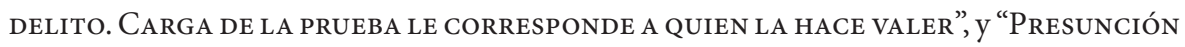
DE inocencia. Alcances de eSte principio constitucional." 
que éstos deben ser analizados de una manera congruente mediante una interpretación armonizadora, de modo que aclara, dicha teoría niega la existencia de conflictos de derechos fundamentales y afirma que éstos deben ser interpretados congruentemente. ${ }^{29}$

Siguió señalando que con base en esa perspectiva, para la resolución de la contradicción se debe atender a los principios que rigen la labor interpretativa tratándose de derechos fundamentales, para lo cual refiere los principios:

- Pro homine en sus dos variantes, de preferencia interpretativa y preferencia normativa.

- De posición preferente de los derechos fundamentales.

- De mayor protección de los derechos fundamentales.

- De fuerza expansiva de los derechos humanos.

De igual modo, dijo tener presente la tendencia expansiva de los derechos fundamentales, de acuerdo con la reforma al artículo 1o. de la Constitución federal que a la fecha en que resolvía no había concluido todavía. ${ }^{30}$

Resolución de la contradicción. De conformidad con todo lo anterior, concluyó que la restricción establecida en el artículo 38, fracción II, de la Constitución federal, interpretada armónicamente con el principio de presunción de inocencia, precisaba ser delimitada.

29 Invocó y transcribió en el cuerpo de la sentencia a Fernando M. Toller, autor de la obra Los derechos son sociables: coexistencialidad y ajustamiento (Una metodología alternativa de interpretación constitucional y toma de decisiones que reconcilie los derechos).

30 Se refiere al Decreto publicado en el Diario Oficial de la Federación el 10 de junio de 2011, por el que se modifica la denominación del Capítulo Primero del Título Primero; el primero y quinto párrafos del artículo 1o.; el segundo párrafo del artículo 3o.; el primer párrafo del artículo 11; el artículo 15; el segundo párrafo del artículo 18; el primer párrafo del artículo 29; el primer párrafo del artículo 33; la fracción décima del artículo 89; el segundo párrafo del artículo 97; el segundo y tercer párrafos del apartado B del artículo 102; y el inciso g, de la fracción segunda del artículo 105; la adición de dos nuevos párrafos, segundo y tercero, al artículo 1o. y recorriéndose los actuales en su orden; un nuevo párrafo segundo al artículo 11, los párrafos segundo, tercero, cuarto y quinto al artículo 29; un nuevo párrafo segundo al artículo 33, recorriéndose el actual en su orden y los nuevos párrafos quinto, octavo y décimo primero, recorriéndose los actuales en su orden, al artículo 102 del Apartado B; todos de la Constitución Política de los Estados Unidos Mexicanos. 
Ello porque dijo que no puede subsistir como una prohibición o restricción absoluta, es decir, restringir el ejercicio de los derechos políticos de manera lisa y llana, en el caso el derecho al voto por el solo dictado del auto de formal prisión, sin distinguir ningún supuesto o condición.

Por tanto, señaló que no bastaba la aplicación del método de interpretación literal para determinar sus extremos constitucionales, ya que las restricciones constitucionalmente definidas deben quedar reducidas a la mínima expresión.

Además, advirtió que en materia penal ha existido, por tradición, una distinción entre aquellos ilícitos cuya sanción permite la libertad provisional bajo caución, siendo un criterio muy aceptado el de la duración de la pena para efectos de determinar si el indiciado puede o no disfrutar de un beneficio de esa naturaleza.

Posteriormente, y por el incremento de la delincuencia, señaló que se ha distinguido entre delitos graves y no graves, como otro de los criterios para determinar si el sujeto tiene derecho o no a gozar de una libertad provisional bajo caución.

Dadas esas distinciones, consideró que el texto constitucional necesitaba ser interpretado también de manera diversa, para que una eventual suspensión de derechos no se prolongue indefinidamente y adquiera las características de una sanción.

Así las cosas, resolvió:

En esa tesitura, si la norma constitucional contempla también la posibilidad de obtener una libertad provisional, distinguiendo si se trata o no de delitos graves, tal criterio debe hacerse extensivo también a lo dispuesto por el artículo 38, fracción II, de la Constitución Federal y distinguir cuándo el dictado de un auto de formal prisión debe restringir también los derechos y prerrogativas del ciudadano, como lo es el derecho al voto, pues si la misma Constitución distingue entre delitos graves o no graves y cuáles permiten, y cuáles no, el disfrute de una libertad provisional bajo caución, no hay razón válida alguna para no realizar esta distinción, tratándose del dictado de un auto de formal prisión, en relación con la suspensión del señalado derecho del ciudadano.

En otras palabras, este Tribunal Constitucional considera que la interpretación de la fracción II, del artículo 38 de la Constitución Federal, 
en cuanto prevé la suspensión del derecho ciudadano a votar cuando se encuentre privado de su libertad en virtud de estar sujeto a un proceso criminal por delito que merezca pena corporal, desde la fecha del auto de formal prisión, debe llevarse a cabo en armonía con el principio de presunción de inocencia; interpretación que descansa en la necesidad de hacer congruentes esos mandamientos constitucionales, guiados, a su vez, por la preponderancia de los derechos fundamentales, ello porque una interpretación diversa impediría el ejercicio de la prerrogativa de votar a los ciudadanos por el solo hecho de estar sujeto a proceso penal a partir del auto de formal prisión, sin distinguir el hecho relativo a que el procesado se encuentre o no efectivamente privado de su libertad, pues si se le otorgó la libertad provisional no se presentaría la razón que justifica la suspensión de tal derecho y que lleva al Constituyente a establecerla como tal en el artículo 38, fracción II, constitucional, el cual, como se señaló, nunca ha sufrido reforma alguna.

La SCJN estimó necesario insistir en que, atendiendo las modernas corrientes humanistas cuyo anhelo es ampliar irrestrictamente los derechos y libertades de los ciudadanos, no resulta conveniente suspender en todos los casos y para todos los procesados el derecho de votar en las elecciones populares, dada la importancia de que los ciudadanos participen en los asuntos políticos del país, como lo es, por antonomasia, la elección de sus autoridades.

De igual modo, explicó que lo resuelto por el pleno de la SCJN, sobre la acción de inconstitucionalidad 33/2009 y sus acumuladas 34/2009 y $35 / 2009$, al sostener que el artículo 38, fracción II, de la ley fundamental, prevé una restricción constitucional, desde el dictado del auto de formal prisión, que exige sólo la probable responsabilidad del inculpado, en forma concordante con el principio de presunción de inocencia, la obligó a atender a la razón que lleva al Constituyente a mantener la causa de la suspensión, que es de eminente orden práctico, consistente en la imposibilidad de llevar casillas electorales a prisión y de lo que ello implica, como son la dificultad de hacer campañas electorales en prisión o elegir a los funcionarios de casilla que deban realizar su función dentro de una prisión.

De ahí, concluyó que la causa de suspensión en análisis exige que el indiciado efectivamente se encuentre privado de su libertad para que no pueda hacer efectiva su prerrogativa de votar en las elecciones 
populares, lo que excluye, evidentemente, a quienes obtengan libertad provisional.

También precisó que en lugar de un auto de formal prisión se podría estar en presencia de un auto de vinculación a proceso en términos de la reforma al artículo 19 de la Constitución federal, según la reforma antes explicada, en virtud del cual, por definición, no es precisa la privación preventiva de la libertad del indiciado. Por ende consideró que con mayor razón, en esta otra situación jurídica resulta evidente que el procesado en libertad goza del derecho al voto, atendiendo al mismo razonamiento práctico arriba apuntado.

Como resultado de todo lo anterior, sentenció que el artículo 38, fracción II, de la Constitución, debe interpretarse en el sentido de que en ningún caso se impide el goce del derecho al voto cuando el inculpado enfrenta el proceso penal en libertad, ya sea como consecuencia del pago de una caución que tenga verificativo con posterioridad al dictado del auto de formal prisión, o como consecuencia del dictado de un auto de mera vinculación a proceso, que, con mayor razón, permite enfrentar dicho proceso sin restricción precautoria de la libertad.

Por todo lo explicado, determinó que el criterio que debe prevalecer es:

Derecho al voto. Se suspende por el dictado del aUto de Formal PRISIÓN O DE VINCULACIÓN A PROCESO, SÓLO CUANDO EL PROCESADO ESTÉ EFECTIVAMENTE PRIVADO DE SU LIBERTAD. El artículo 38, fracción II, de la Constitución Política de los Estados Unidos Mexicanos establece que los derechos o prerrogativas del ciudadano se suspenden, entre otros casos, por estar sujeto a un proceso criminal por delito que merezca pena corporal, a partir de la emisión del auto de formal prisión. Por su parte, el principio de presunción de inocencia y el derecho a votar constituyen derechos fundamentales, cuya evolución y desarrollo constitucional llevan a atemperar la citada restricción constitucional. Ahora bien, la interpretación armónica de tal restricción con el indicado principio conduce a concluir que el derecho al voto del ciudadano se suspende por el dictado del auto de formal prisión o de vinculación a proceso, sólo cuando el procesado esté efectivamente privado de su libertad, supuesto que implica su imposibilidad física para ejercer ese derecho, lo que no se presenta cuando está materialmente en libertad, supuesto en el cual, en tanto no se dicte una sentencia condenatoria, no existe impedimento para el ejercicio del derecho al sufragio activo. 


\section{Reflexiones}

Una vez que han quedado explicados los criterios que entraron en contradicción, así como las razones que soportan la jurisprudencia resultante, no me resta más que hacer algunos breves comentarios, que tienen como objeto esbozar algunas ideas que próximamente podrían ser retomadas con motivo de lo provechoso del presente caso para el conocimiento y resolución de futuros casos o estudios.

En primer lugar quisiera precisar que en mi concepto con la resolución adoptada por el pleno de la Suprema Corte de Justicia de la Nación, se han potencializado los derechos de los ciudadanos y se les protege de una mejor manera, en efecto, considero pertinente mencionar que si a una persona a la que se le ha dictado auto de formal prisión, se le concede la libertad, que es el bien de mayor valor después de la vida, no existe razón para que se le prive de otros derechos.

De la jurisprudencia obligatoria para el TEPJF. Quisiera comenzar estos comentarios señalando, que no paso por alto el criterio del alto tribunal respecto a la obligatoriedad para el TEPJF de la jurisprudencia derivada de las acciones de inconstitucionalidad. Considero opinable que se generara ese criterio, cuando el mismo no sería útil para resolver la contradicción de criterios apuntada, pues el propio pleno de la SCJN reconoció que las interpretaciones realizadas en las acciones de inconstitucionalidad 33/2009 y sus acumuladas, por sus características, no eran idóneas para resolver los criterios confrontados entre la Sala Superior del TEPJF y la Primera Sala de la SCJN.

Desde mi perspectiva, la razón que pudo sustentar un criterio sobre ese tema, debió obedecer a su utilidad para resolver la mencionada contradicción de criterios que se sometía a su conocimiento y resolución.

La interpretación del artículo 38, fracción II, constitucional. Por otro lado, después de conocer los criterios en contradicción y su resultante, es posible concluir que mientras la Primera Sala de la SCJN antepuso la aplicación literal del artículo 38, fracción II, constitucional, en razón de un criterio exclusivamente jerárquico, por otro lado, primero la Sala Superior y, posteriormente, el pleno de la SCJN, determinaron interpretar ese dispositivo junto con lo previsto en los tratados internacionales en materia de derechos humanos, con la finalidad de atri- 
buirle un significado acorde con una actualidad cuya mayor exigencia es el respeto y la más amplia tutela de los derechos humanos.

En ese contexto, es dable sostener que las limitaciones al ejercicio de los derechos humanos relacionados con la materia electoral, aún las de carácter constitucional, deben ser interpretadas y aplicadas de la forma más restringida posible. Dicho en otras palabras, el pleno de la SCJN confirmó el criterio impulsado por el TEPJF respecto del artículo 38, fracción II, constitucional, en el sentido que el texto de la ley suprema que contempla limitaciones al ejercicio de los derechos político electorales, puede ser interpretado y aplicado, en armonía con las previsiones existentes en los tratados internacionales en materia de derechos humanos.

De las soluciones a futuros casos. En otra parte, también es posible considerar que la ratio essendi de dicha jurisprudencia podría ser invocada como un poderoso soporte para resolver futuros casos en los que se encuentren involucrados otros derechos político-electorales de los ciudadanos distintos al de votar como son, por mencionar algunos, los de ser votado, afiliación y asociación, en relación con la restricción a que se refiere el artículo 38, fracción II, constitucional.

Tampoco debe pasarse por alto que la interpretación que fijó el Comité de Derechos Civiles y Políticos de la Organización de Naciones Unidas sobre el alcance normativo del artículo 25 del Pacto de Derechos Civiles y Políticos, en la observación general número 25 de su 57 periodo de sesiones de 1996, fue que "a las personas a quienes se prive de la libertad pero que no hayan sido condenadas no se les debe impedir que ejerzan su derecho a votar".

Seguramente, en un futuro cercano podríamos estar enfrentando casos en los que sea necesario reconocer y ordenar instrumentar todo lo necesario para que, quienes se ubiquen en ese supuesto, tengan expedito el ejercicio de ese derecho.

Para terminar, debe tenerse en cuenta que el efecto inmediato de la jurisprudencia resultante de la presente contradicción, obliga a todos los jueces penales del país a aplicarla, no obstante que en las legislaciones locales se establezcan casos más severos o de restricción más amplia o, en su defecto, corresponderá a las salas regionales del TEPJF aplicar ese criterio, en los juicios para la protección de los derechos político electorales del ciudadano que se promuevan en contra de las determinaciones de la Dirección Ejecutiva del Registro Federal de Electoral del IFE cuando se observen casos similares al aquí expuesto. 


\section{Bibliografía y otras fuentes}

Código Federal de Instituciones y Procedimientos Electorales vigente hasta el 14 de enero de 2008.

Código Federal de Instituciones y Procedimientos Electorales vigente a partir del 15 de enero de 2008.

Compilación 1997-2010 Jurisprudencia y tesis en materia electoral, publicado por el TEPJF.

Decreto publicado en el Diario Oficial de la Federación el 10 de junio de 2011, por el que se modifica la denominación del Capítulo Primero del Título Primero; el primero y quinto párrafos del artículo 1o.; el segundo párrafo del artículo 3o.; el primer párrafo del artículo 11; el artículo 15; el segundo párrafo del artículo 18; el primer párrafo del artículo 29; el primer párrafo del artículo 33; la fracción décima del artículo 89; el segundo párrafo del artículo 97; el segundo y tercer párrafos del apartado B del artículo 102; y el inciso g) de la fracción segunda del artículo 105; la adición de dos nuevos párrafos, segundo y tercero, al artículo 1o. y recorriéndose los actuales en su orden; un nuevo párrafo segundo al artículo 11, los párrafos segundo, tercero, cuarto y quinto al artículo 29; un nuevo párrafo segundo al artículo 33, recorriéndose el actual en su orden y los nuevos párrafos quinto, octavo y décimo primero, recorriéndose los actuales en su orden, al artículo 102 del Apartado B; todos de la Constitución Política de los Estados Unidos Mexicanos.

Ley General del Sistema de Medios de Impugnación en Materia Electoral.

Ley Orgánica del Poder Judicial de la Federación.

Ley Federal de Transparencia y Acceso a la Información Pública Gubernamental.

Sentencia dictada por la Sala Superior del TEPJF el 20 de junio de 2007, en el expediente SUP-JDC-85/2007, en: $h t t p: / / 200.23 .107 .66 /$ siscon/gateway.dll/nSentencias/nSuperior/nSENSUP2007/jdc.

Sentencia dictada por la Primera Sala de la SCJN en la contradicción de criterios 29/2007-PS, en: http://www2.scjn.gob.mx/juridica/engroses/cerrados/publico/0700029P.S04.doc.

Sentencia dictada por el pleno de la SCJN el 28 de mayo de 2009, en las acciones de inconstitucionalidad 33/2009, y sus acumuladas 
34/2009 y 35/2009, en: http://www2.scjn.gob.mx/juridica/engroses/ cerrados/103/09000330.019.doc.

Sentencia dictada por el pleno de la SCJN en la contradicción de criterios 6/2008-PL, en: http://www2.scjn.gob.mx/juridica/engroses/ cerrados/publico/0800006P.L04.doc. 